\title{
DO PENSAMENTO SISTEMÁTICO AO PENSAMENTO SISTÊMICO E SEUS REFLEXOS NA CIÊNCIA DO DIREITO
}

\section{DEL PENSAMIENTO SISTEMÁTICO AL PENSAMIENTO SISTÉMICO Y SUS EFECTOS SOBRE LA CIENCIA DEL DERECHO}

${ }^{1}$ Ana Carolina Oliveira Gomes

\section{RESUMO}

O artigo distingue o pensamento sistemático, paradigma tradicional de ciência, caracterizado pelos pressupostos da simplicidade, estabilidade e objetividade, do pensamento sistêmico, novo paradigma científico, cujos pressupostos são a complexidade, instabilidade e intersubjetividade. Por meio de uma revisão bibliográfica acerca do sistema jurídico desde o direito romano até a atualidade, demonstra como a ciência do direito também é influenciada pelas mudanças paradigmáticas das ciências em geral. Identifica o direito pré-moderno ao pensamento problemático; o direito moderno ao pensamento sistemático; e aponta nas correntes jurídicas contemporâneas uma tendência à atenuação dos pressupostos do pensamento sistemático para assunção gradual dos pressupostos do pensamento sistêmico. Ao final, constata que a proposta de alguns juristas contemporâneos quanto ao modo de aplicar o direito é a conciliação entre os pensamentos sistemático e o problemático, num viés sistêmico.

Palavras-chave: Direito, Ciência, Paradigma, Pensamento sistemático, Pensamento sistêmico

\section{RESUMEN}

El artículo distingue el pensamiento sistemático, paradigma tradicional de la ciencia, caracterizado por los presupuestos de la simplicidad, estabilidad y objetividad; del pensamiento sistémico, nuevo paradigma científico, cuyos presupuestos son la complejidad, inestabilidad e intersubjetividad. Por medio de una revisión bibliográfica del sistema jurídico, desde el derecho romano hasta la actualidad, se demuestra como la ciencia del derecho también es influenciada por los cambios paradigmáticos de la ciencia en general. Identifica el derecho pre moderno al pensamiento problemático; el derecho moderno al pensamiento sistemático; y apunta en las corrientes contemporáneas del derecho una tendencia a la atenuación de los presupuestos del pensamiento sistemático para asumir gradualmente las características del pensamiento sistémico. Al final, constata la propuesta de algunos juristas contemporáneos en cuanto al modo de aplicar el derecho y la conciliación entre los pensamientos: sistemático y problemático en un sesgo sistémico.

Palabras-claves: Derecho, Ciencia, Paradigma, Pensamiento sistemático, Pensamiento sistémico

\footnotetext{
1 Graduada em Direito pela Universidade Federal de Uberlândia. Procuradora do Estado de Minas Gerais. Universidade Federal de Uberlândia - UFU, Uberlândia, Minas Gerais. Brasil.

E-mail: anacarolina_acog@yahoo.com.br
} 


\section{Introdução}

Traçar um quadro sintético de referência de diversas teorias jurídicas, desde o direito romano até a contemporaneidade, investigando as mudanças paradigmáticas na ciência do direito e a relação dessas com as mudanças ocorridas nas ciências em geral é o que se pretende.

Para tal fim, a primeira parte da pesquisa é dirigida a uma breve explicação dos paradigmas de ciência em geral: primeiro, o paradigma tradicional - o pensamento sistemático, que tem como pressupostos a simplicidade, a estabilidade e a objetividade; segundo, o "novo" paradigma - o pensamento sistêmico, que tem por pressupostos a complexidade, a instabilidade e a intersubjetividade, e, como origem, as teorias mecanicistas e organicistas, cujos principais expoentes são mencionados.

A seguir, passa-se a uma sucinta revisão bibliográfica sobre os variados modelos e propostas jurídicas que se articularam através dos séculos, no intuito de criar um panorama geral no qual se possa esquadrinhar como as mudanças paradigmáticas estão profundamente relacionadas com o acúmulo e a interação do conhecimento no tempo e no espaço, e como o modo de pensar pode influenciar o modo de aplicar o direito.

Aliás, a reflexão proposta gravita em torno dos seguintes questionamentos: as mudanças paradigmáticas das ciências em geral têm reflexos na ciência jurídica? Como o direito tem incorporado os pressupostos do pensamento sistêmico? Será que essa nova forma de pensar será capaz de gerar uma nova forma de fazer, isto é, uma nova prática jurídica?

Todas essas indagações foram proporcionadas pela leitura do livro Pensamento sistêmico: o novo paradigma de ciência, da psicóloga mineira Maria José Esteves de Vasconcellos, que, juntamente, com os três volumes da obra Sistema e estrutura no direito, de Mario G. Losano, constituem o referencial teórico desse artigo. Destaque-se, entretanto, que esses dois referenciais serviram apenas de estímulo a uma árdua, mas venturosa revisão bibliográfica que se seguiu e cuja "síntese da síntese" é a apresentada nas próximas páginas.

\section{Pensamento Sistemático. O Paradigma Tradicional de Ciência}

As bases do pensamento científico ocidental moderno estão localizadas na Antiguidade Clássica, aproximadamente no período compreendido entre os séculos VIII a.C. e VI a.C., na Grécia antiga, quando os pensadores da Escola de Mileto (Thales, Anaximandro e Anaxímenes) iniciaram uma tentativa de compreender o mundo por meio da razão, 
inaugurando a passagem do mito para o $\log o s$, que só foi consolidada, entre os séculos V a.C. e IV a.C., em Atenas, com Sócrates, Platão e Aristóteles. Desse modo, foi na Grécia Antiga que se forjou a ideia de que a forma válida de conhecer o mundo é a que se dá mediante a razão. Considera-se, portanto, que os gregos lançaram os alicerces para a racionalidade ocidental, tradição herdada e conservada, nos séculos seguintes, pelos romanos (BARROSO, 2012, p. 26).

Ocorre que, com a consolidação do cristianismo no Ocidente e o advento do período histórico conhecido como Idade Média, impôs-se a conciliação entre as "verdades de fé" e as da razão, construindo-se uma filosofia de tipo religioso, que se afastava padrão de racionalidade iniciado pelos gregos. Por conseguinte, esse modelo de racionalidade científica apenas teve nova inflexão no século XVII, quando os estudos de Descartes (1596/1650) redundaram na separação entre filosofia, cujo método é especulativo, e ciência, cujo método matemático ou empíricopositivo (VASCONCELLOS, 2002, p. 59).

Na Idade Moderna, empreendeu-se à busca de um padrão de racionalidade que fosse universal e pudesse ser estendido a todos os domínios do conhecimento, do universo físico ao social, político e moral. "Esse projeto se dirigiu primeiro ao mundo das coisas: astronomia (física celeste) e física (física terrestre), nos séculos XVI e XVII; em seguida ao mundo dos homens: ciências humanas, nos séculos XVII e XVIII." (VASCONCELLOS, 2002, p. 60).

A pretensão de rigor, precisão e universalidade do conhecimento, por meio da racionalidade, levaram os cientistas modernos a formularem métodos que garantissem atingir a certeza e os fundamentos do conhecimento. Com o desenvolvimento da noção de método científico, houve a institucionalização da ciência moderna ou tradicional, cujos paradigmas podem ser sintetizados em três pressupostos: o da simplicidade, o da estabilidade e o da objetividade (VASCONCELLOS, 2002, p. 74-94).

O pressuposto da simplicidade significa que a ciência procede à análise dos todos complexos, mediante a fragmentação do objeto a ser conhecido em partes e, a partir dessas partes, elementos mais simples, estabelece relações causais lineares e unidirecionais. Desse 
pressuposto, decorre, por exemplo, a fragmentação e especialização do conhecimento científico em áreas ou disciplinas específicas e estanques. O pressuposto da estabilidade parte da crença de que o mundo é estável e ordenado e que suas leis de funcionamento, simples e imutáveis, podem ser conhecidas, estabelecendo-se relações funcionais, que permitem a previsibilidade, controlabilidade e reversibilidade dos fenômenos. O pressuposto da objetividade funda-se na crença de que é possível conhecer o mundo tal como ele é na realidade, buscando-se atingir uma versão única do conhecimento, por meio do distanciamento entre o sujeito e o objeto do conhecimento.

Tais pressupostos desenvolveram-se, primeiramente, no campo das ciências físicas e, em seguida, foram impostos às demais disciplinas como modelo de cientificidade.

De fato, as ciências físicas, por muito tempo, aprimoraram-se lastreadas nesses três pressupostos, alcançando grande progresso e, por isso, sendo consideradas como o padrão de racionalidade e de método científico a ser seguido por todos os campos das ciências.

No entanto, se, para as ciências físicas, a utilização dos pressupostos da simplicidade, estabilidade e objetividade ajustava-se perfeitamente, o mesmo não se verificava no campo das ciências biológicas e das ciências humanas, que encontravam dificuldades para o estudo da complexidade crescente dos seres vivos e da dinâmica própria dos fenômenos humanos e sociais sob a perspectiva racional imposta por tais pressupostos.

Não obstante, desde que foi estabelecido, aproximadamente no século XVII da era cristã, o paradigma moderno de racionalidade tem sido o viés preferencial pelo qual os cientistas buscam o conhecimento, tendo impregnado também a visão de mundo do senso comum.

\section{Pensamento Sistêmico. O Novo Paradigma de Ciência}

Conquanto os pressupostos da objetividade, simplicidade e estabilidade continuem vigentes nos pensamentos científico e comum da atualidade, é preciso destacar que, especialmente a partir da segunda metade do século $\mathrm{XX}$, um grupo de pensadores de vários campos do conhecimento começou a questionar os paradigmas tradicionais de ciência, desencadeando o início de uma virada epistemológica e o surgimento de novos pressupostos para a racionalidade científica.

Com relação ao pressuposto da simplicidade, inicia-se um processo de reconhecimento de que o ideal racional moderno de simplificação não corresponde à realidade dos fenômenos, que é complexa (e, na contemporaneidade, cada vez mais complexa). 
Constata-se que, na verdade, a pretensão de simplificação do objeto do conhecimento, de redução ou eliminação dos paradoxos e contradições, de distinção do objeto do conhecimento do seu contexto acabou por obscurecer o conhecimento da natureza e dos fenômenos. Por conseguinte, passa-se a defender o abandono da pretensão de simplicidade para assunção do pressuposto da complexidade, o que implica numa atitude de reintegração do objeto ao seu contexto, colocando o foco nas inter-relações de fato existentes entre os fenômenos e entendendo que a causalidade do mundo complexo não é linear e unidirecional, mas circular e recursiva (VASCONCELLOS, 2002, p. 104-118).

No mesmo sentido, deixa-se de insistir na crença da estabilidade, ordenação e controlabilidade do mundo e de seus fenômenos, admitindo-se que o mundo está em constante processo de transformação, decorrendo disso a indeterminação, a imprevisibilidade e a impossibilidade de controlar diversos fenômenos. Passa-se do pressuposto da estabilidade para o da instabilidade (VASCONCELLOS, 2002, p. 118-129).

Nesse novo paradigma de ciência, renuncia-se também à crença de que é possível o conhecimento objetivo da realidade, aceitando-se o fato de que a construção do conhecimento alicerça-se na intersubjetividade. Isso significa, num primeiro momento, assumir que "não existe uma realidade independente de um observador" e, num segundo momento, confessar que a ciência "jamais será um espaço da verdade, mas um espaço de consenso", ou seja, que há várias versões da realidade, “em diferentes domínios linguísticos de explicações”, e que o conhecimento científico será sempre uma construção social de validação das experiências subjetivas de diferentes sujeitos/observadores, em espaços consensuais (VASCONCELLOS, 2002, p. 129-144).

Nesse ponto, é preciso repetir que a afirmação da complexidade, instabilidade e intersubjetividade como pressupostos do novo paradigma de ciência é fruto de experiências e discussões conjuntas em campos científicos diversos, sendo que a interdisciplinariedade, além de característica marcante, foi fundamental para o desenvolvimento dessas novas propostas teóricas, nominadas de teorias sistêmicas e cujas expressões mais conhecidas são a Teoria Geral dos Sistemas da Natureza, a Cibernética da Cibernética e a Teoria da Autopoiese.

Identifica-se como origem das teorias sistêmicas, com "vocação transdiciplinar", duas vertentes que foram construídas concomitantemente no decorrer do século XX: a organicista, voltada ao conhecimento dos organismos ou sistemas naturais, biológicos ou sociais e associada à Teoria Geral dos Sistemas; e a mecanicista, voltada à criação dos sistemas artificiais e associada às Teorias Cibernéticas. 
Como representante da vertente organicista, Ludwig Von Bertalanffy (1901/1972), biólogo austríaco e autor da Teoria Geral dos Sistemas, é "unanimemente reconhecido como um dos teóricos pioneiros dos sistemas", sendo que datam da década de 20 suas primeiras publicações no sentido de estabelecer as premissas para um novo paradigma de ciência. Entretanto, seu reconhecimento como teórico da nova abordagem só ocorreu, em 1968, com a publicação de seu livro mais conhecido, a Teoria Geral dos Sistemas (VASCONCELLOS, 2002, p. 186)

Bertalanffy, criticando uma visão científica dividida em áreas cada vez mais específicas e que não se comunicavam, propôs uma teoria de princípios básicos interdisciplinares e universais, que visavam à unidade da ciência e seriam aplicáveis aos sistemas em geral, quais sejam, o físico, biológico e sociológico (BERTALANFFY, 2009).

O autor, por meio da observação dos sistemas vivos, enfatizou a importância de se perceber que o comportamento do todo é mais complexo do que a soma dos comportamentos das partes, teorizando sobre os conceitos de organismo e de sistema; sobre a distinção entre sistemas aberto e fechado e entre sistema e ambiente; sobre a possibilidade de existir sistemas dentro de sistemas; sobre o "lugar de relação ou troca" entre o sistema e o ambiente ou dos sistemas entre si (interações intersistêmicas). Em síntese, Bertalanffy lançou as bases para uma Teoria Geral dos Sistemas da Natureza, mais tarde desenvolvida na "Biologia do Conhecer" e na "Teoria da Autopoiese”, de Humberto Maturana e Francisco Varela.

$\mathrm{Na}$ vertente mecanicista, destaca-se, num primeiro momento, as formulações do matemático americano, Norbert Wiener (1894/1964), que, ao publicar sua obra Cibernética e Sociedade, em 1950, conduziu os conceitos cibernéticos, tais como feedback (retroalimentação) positivo ou negativo, processos morfostáticos (capacidade de autoestabilização ou auto-manutenção do sistema), processos morfogenéticos (capacidade de automudança do sistema), para além do domínio da tecnologia, estendendo-os aos campos biológico e social (WIENER, 1973). É preciso destacar que a Cibernética, tal como desenvolvida por Wiener, teve por mérito deslocar o foco da ciência para as relações e representar, no campo das ciências físicas, um esforço interdisciplinar, embora não tenha logrado êxito em ultrapassar "o paradigma da ciência tradicional, mantendo-se determinista e objetivista" (VASCONCELLOS, 2002, p. 218).

Mister consignar também que a explicação cibernética de auto-organização do sistema era distinta da explicação de auto-organização dos sistemas naturais, que, na visão de Bertalanffy, incorporava, igual e constantemente, a estabilidade e a mudança, a preservação e a transformação. 
Num segundo momento da vertente cibernética, aproximadamente na década de 70 , formou-se um contexto mais propício ao desenvolvimento dos três novos paradigmas de ciência já apresentados. Conhecida como Cibernética de Segunda Ordem ou Cibernética da Cibernética e tendo como principal expoente o físico austríaco Heinz Von Foerster (1911/2002), esse foi o momento do "giro de auto-referência" e da construção das bases para uma "teoria do observador", no sentido de "assumir que tudo que se dizia sobre um sistema estava relacionado com as propriedades do cientista para fazer essa observação" (VASCONCELLOS, 2002, p. 243). Percebe-se, portanto, o ambiente adequado para a consolidação da ideia de que não seria possível atingir a realidade por meio da objetivação, tampouco instruir e controlar o sistema, sendo necessário aceitar também a abordagem da instabilidade e da complexidade.

O segundo momento da vertente organicista é representado pela Teoria da Autopoiese, que começou a ser desenvolvida na década de 50, por meio dos estudos de neurofisiologia da visão do biólogo chileno Humberto Maturana (1928). Após publicar suas idéias em 1970, Maturana iniciou uma longa cooperação científica com Francisco Varela (1946/2001), neurocientista chileno da Universidade de Santiago. Os dois empreenderam à descrição formal completa do arcabouço conceitual articulado e consistente sobre a ideia de Maturana acerca da teoria biológica sistêmica e o tema da auto-organização, inventando o termo autopoiese para nomear essa nova teoria, em que auto significa "si mesmo" e se refere à autonomia dos sistemas auto-organizadores, e poiese significa "criação", "construção" (CAPRA, 1996, p. 77). Os conceitos fundamentais da Teoria da Autopoeise podem ser sintetizados em três - organização autopoiética, fechamento estrutural e acoplamento estrutural - e estão desenvolvidos na obra de A árvore do conhecimento: as bases biológicas do entendimento humano (MATURANA; VARELA, 1995).

Em síntese, em que pese a Teoria da Autopoiese ter sido construída como teoria biológica e a Cibernética de Segunda Ordem ter sido desenvolvida no campo das ciências físicas, seus conceitos e observações tiveram implicações epistemológicas e ontológicas, no sentido de que provocaram mudanças na forma e no objeto do conhecimento, causando uma verdadeira virada paradigmática, por ter redundado na modificação dos pressupostos de ciência, como já explicado.

Nessa alheta, o sociólogo norte-americano Talcott Parsons (1902/1979) foi um dos primeiros a aplicar os princípios oriundos da Teoria dos Sistemas e da Cibernética ao campo da observação dos sistemas sociais. Entretanto, coube ao sociólogo alemão Niklas Luhmann (1927/1998), incorporando muitos dos conceitos desenvolvidos pelos pensadores das 
vertentes organicistas e mecanicistas, construir uma verdadeira teoria geral do conhecimento no viés sistêmico, que excedeu os limites da sociologia, haja vista o alto grau de abstração do seu intricado aparato conceitual. Luhmann adequou os conceitos da autopoiese biológica à realidade dos fenômenos sociais, distinguindo o sistema biológico, cujo elemento constitutivo é a vida, do sistema social, no qual a base reprodutiva é a comunicação (LUHMANN, 2011, p. 213). Assim, define a sociedade como um sistema autopoiético (LUHMANN, 2011, p. 112127) e, como tal, um sistema operativamente fechado e cognitivamente aberto, o que se aplica a cada um dos subsistemas, dentre os quais, está o Direito. Importante destacar que tanto a linguagem, quanto a trama conceitual do arcabouço teórico luhmanniano apresentam um elevado grau de dificuldade, o que faz com que a leitura de suas obras seja um desafio, não muito cativante para grande parte dos leitores e críticos.

Aliás, é interessante observar como, nos últimos anos, as ciências sociais vêm ganhando preeminência. LOSANO destaca que, examinando as obras da pós-modernidade, percebe-se que "os grandes sistemas abrangentes não são mais produzidos por filósofos, e sim por sociólogos" (LOSANO, 2011, p. XVII) e destaca que, além de Luhmann, devem ser citados outros dois importantes sociólogos pós-modernos: o polonês Zygmunt Bauman (1925) e o francês Edgar Morin (1921).

Zygmunt Bauman é conhecido por caracterizar a sociedade pós-moderna como líquida em oposição àquela da Idade Moderna, que poderia ser considerada sólida. Segundo o autor, a pós-modernidade é caracterizada pela velocidade e fluidez das transformações sociais, o que faz com que o ser humano tenha de se adaptar constantemente, impedindo que seus modos de agir possam consolidar-se em hábitos e procedimentos, gerando todo tipo de instabilidade, como a grande efemeridade nas relações sociais; a fragilidade do controle social e de todo tipo de das regras, sejam éticas, sociais ou jurídicas; e o medo de não ser possível adaptar-se e sobreviver à tamanha instabilidade (LOSANO, 2011, p. XVII/XIX). Com efeito, Bauman é um grande crítico dos impactos do capitalismo e do consumismo nas relações sociais.

As pesquisas de Edgar Morin dão ênfase à questão da complexidade do mundo moderno, que ele entende não como o oposto da simplicidade, tampouco como expressão aproximada de completude; para o autor, todo conhecimento é fatalmente provisório, inacabado e incompleto; e a complexidade deve ser vista como transdiciplinariedade, não sendo adequado à ciência a tendência cartesiana e positivista de seccionar e simplificar dos fenômenos (LOSANO, 2011, p. XIX/XXII). 
Em síntese, enquanto Luhmann propõe uma nova forma de sistematicidade dos fenômenos sociais, adotando a teoria da autopoiese; Morin enfatiza a questão da complexidade, na linha da transdiciplinariedade; e Baumann destaca os aspectos da instabilidade, fragmentariedade e provisoriedade das relações sociais. Ressalte-se ainda que as elaborações científicas de Luhmann têm maiores reflexos na ciência do direito, porquanto Luhmann teve formação jurídica e escreveu especificamente sobre a sociologia do direito.

Enfim, todo o esforço até agora realizado para demonstrar a mudança paradigmática no campo das ciências, visa a compreender qual o impacto disso na ciência jurídica, bem como refletir sobre a melhor forma de observar e aplicar o direito na sociedade do século XXI.

\section{O Direito Pré-Moderno. Pluralismo Jurídico e Pensamento Problemático}

Consoante o exposto, na Grécia Antiga estão as origens do padrão de racionalidade que orientou o pensamento científico da modernidade; na Idade Média, houve um distanciamento desse paradigma de ciência iniciado pelos gregos, provocado pela tentativa de conciliação entre o pensamento científico-filosófico e o religioso; posteriormente, na Idade Moderna, retoma-se a ênfase na racionalidade pura, que se firma como o modo exclusivo de conhecimento científico, em todas as suas dimensões. O Direito não ficou a margem desse processo de mudanças epistemológicas.

Embora o propósito seja investigar os reflexos dos paradigmas científicos modernos na ciência do direito, é interessante fazer uma digressão, expondo alguns aspectos do direito pré-moderno.

Depreende-se dos escritos filosóficos e da literatura da Grécia Clássica, que, nessa civilização, estava presente a ideia da existência de uma dualidade de ordens: o direito posto pelos governantes das polis e, de outro lado, o direito natural, compreendido como uma lei eterna, racional e imutável, como tão bem retratado na Trilogia Tebana, de Sófocles (SÓFOCLES, 2001). Das fontes que sobreviveram ao tempo, sabe-se também que algumas cidades gregas da Antiguidade conheceram leis escritas, organização judiciária e regras de julgamento.

Entre os séculos I a.C. e III d.C., no Império Romano, o direito conheceu uma “época áurea”. O direito romano estava fundamentado em poucas leis escritas (ius civile) e numa vasta e casuística elaboração jurisprudencial (ius praetorium), que dizia a justiça do 
caso concreto e foi constituindo-se como fonte imediata e autônoma de direito (HESPANHA, 2005, p. 125).

Com a crise do Império Romano, a partir do século III d.C. e sua ulterior queda no Ocidente, no século V d.C., "esse saber jurídico, cujo rigor exigia uma grande formação linguística, cultural e jurídica, e cujo casuísmo impedia uma produtividade massiva" vai perdendo força e, progressivamente, vai ganhando espaço um direito mais simplificado, mais acessível à aplicação por leigos, ou seja, o direito vai vulgarizando-se, "em virtude das corruptelas provocadas pela influência dos direitos locais" (HESPANHA, 2005, p. 126).

Em meados do século VI, o Imperador Justiniano empreendeu a uma tentativa de salvaguarda do direito romano clássico, promovendo a compilação das obras encontradas dos juristas romanos, o que foi nominado de Digesto ou Pandectas, complementando esse acervo com um manual de introdução, conhecido como Instituições. Essa coletânea constituiu-se, posteriormente, na memória medieval e moderna do direito romano e, a partir do século XVI, ficou conhecida como Corpus iuris civilis.

Durante a Idade Média, o que se percebe é um intenso pluralismo jurídico. De um lado, havia o direito comum (jus commune), fruto do trabalho realizado pelos juristas das Escolas, a dos Glosadores e dos Comentadores, no estudo Corpus iuris civilis, mas que também incorporava muito do Direito Canônico, com suas plúrimas fontes, e alguns institutos dos direitos tradicionais dos povos europeus. Concomitantemente, "continuavam em pleno desenvolvimento direitos próprios, fundados em tradições jurídicas romano-vulgares, canônicas e germânicas ou simplesmente nos estilos locais de normação e de resolução de litígios" (HESPANHA, 2005, p. 146).

Pronunciando-se sobre o pluralismo de fontes jurídicas na Idade Média, HESPANHA (2005, p. 142/147) explica que a compatibilização da vigência de todas estas ordens jurídicas reais, municipais, corporativas ou mesmo familiares com o direito comum davase pela primazia dos direitos próprios sobre o direito comum, sendo que esse cumpria o papel de um direito subsidiário e direito modelo, uma vez que o direito romano, que instruía a maior parte do direito comum, era visto como um direito de "superior perfeição".

Depreende-se do acima exposto que o pensamento jurídico medieval até o século XIII era do tipo problemático e não sistemático, ou seja, não havia uma preocupação com uma integração lógica e sistemática entre as soluções encontradas nas diversas searas jurídicas, interessando mais a adequação das soluções jurídicas aos dados concretos do problema que se apresentava (HESPANHA, 2005, p. 225). 


\section{O Direito e a construção do pensamento sistemático}

Durante o Renascimento, período compreendido entre os séculos XIV e XVI, há uma acentuada revalorização das referências culturais da antiguidade clássica, especificamente, do racionalismo e do humanismo, o que tem impacto na ciência do direito, provocando grandes modificações.

O período é marcado pela rejeição à postura erudita, de caráter analítico, atomista $\mathrm{e}$ não metódico do saber jurídico dos Comentadores no estudo do direito romano. Há uma segunda reacriação do direito romano, mas, agora, inspirada no idealismo platônico, na tradição jusnaturalista e na tentativa de construção racional e sistemática do direito (HESPANHA, 2005, p. 256/257).

Assim, no século XVI, é perceptível o distanciamento de alguns juristas da ordem tradicional do Corpus juris e a tentativa de organização do material jurídico tendo como objetivo não as fontes, mas um método e um sistema. Esses juristas tentavam reconduzir cada elemento jurídico disperso a princípios mais gerais, numa formação indutiva do sistema jurídico; nos séculos XVII e XVIII, tais princípios serão assumidos, pelas escolas jusracionalistas, como axiomas jurídicos a partir dos quais se deve proceder dedutivamente (HESPANHA, 2005, p. 235).

Ademais, com a formação dos Estados centralizados, paulatinamente, os ordenamentos jurídicos nacionais são organizados, podendo-se citar as Ordenações Afonsinas, do século XV, como um dos primeiros ensaios de lei nacional codificada sistematicamente na Europa.

$\mathrm{Na}$ transição do Estado absolutista para o Estado liberal, o jusnaturalismo racionalista dos séculos XVII e XVIII constituiu a matriz teórica para o movimento de codificação do Direito no século XIX, o que, paradoxalmente, representou a superação histórica do jusnaturalismo e a afirmação e consolidação do positivismo jurídico (BARROSO, 2012, p. 251).

Com o positivismo jurídico, explicitamente o foco passa a ser a busca da sistematização, tanto no campo normativo, quanto na seara da dogmática, como uma forma de se alcançar uma ordenação e unidade do sistema jurídico, proporcionando-se simplificação, uniformidade, segurança e justiça na aplicação do direito.

Nessa alheta, é de se ver que o movimento de direito legislado do século XIX ocorreu, primeiramente, nas nações em que havia um Estado centralizado, o que não era o caso de algumas nações europeias, como a Alemanha e a Itália, que só passaram 
peloprocesso de formação de um Estado centralizado anos mais tarde. Nessas nações, sobretudo na Alemanha, o elemento de identidade, a "alma nacional" não estava no Estado centralizado e num ordenamento jurídico artificialmente organizado, mas o "espírito do povo", traduzido em suas manifestações culturais.

Por conseguinte, o século XIX conheceu, além da Escola da Exegese surgida na França após o Código de Napoleão, marcada por um forte legalismo, a Escola Histórica Alemã, que era antilegalista e partia do pressuposto de que as normas jurídicas eram encontradas na tradição e nos costumes, valorizando sobremaneira os aspectos consuetudinário e doutrinal do direito e as fontes romanas. O jurista alemão Savigny (1779/1861) é o maior nome da Escola Histórica, sendo responsável pela criação e desenvolvimento de um sistema de conceitos jurídicos, como fato jurídico e relação jurídica, até hoje presentes na dogmática jurídica.

Em que pesem as diferenças acerca do ponto de partida, ambas as Escolas "desembocaram, por igual, num sistema rígido de fetichismo pelos textos e de construção sistemática, apregoando o uso do método dedutivo e exigindo a aplicação das leis de acordo com um processo rigorosamente silogístico" (DINIZ, 2007, p. 55), podendo ambas serem consideradas precursoras do positivismo jurídico que vigorará no século XX.

Acerca da evolução do direito na passagem do século XIX ao XX, LOSANO (2008, p. XXVI) explica que, em parte, há uma continuidade da visão sistemática do direito, representada pela teoria pura do direito, que está fundamentada no pensamento do século XIX, no que se refere ao padrão de racionalidade adotado e por estar a estrutura em degraus de Kelsen enraizada diretamente em autores do século XIX, como Merkl, Gerber, Laband e Jellinek. Contudo, a noção de sistema se transforma: do "sistema oitocentista para dizer o direito", voltado para a organização de um aglomerado de normas, um sistema externo, didático, verdadeira teoria geral, pressionado por uma sociedade em constante transformação, cuja demanda era a melhor forma de aplicar o direito para o "sistema novecentista para fazer o direito", um sistema interno ao direito, que pertence apenas ao próprio direito, instrumento não para o conhecimento, mas para a aplicação do direito (LOSANO, 2010, p. XXIX/XXX).

Hans Kelsen (1881/1973) destaca-se como grande teórico do positivismo jurídico, tendo deslocado o eixo da pesquisa jurídica da norma para o ordenamento, da fragmentariedade à sistematicidade do direito (LOSANO, 2008, p. XXIX). Seu pensamento sistemático está voltado para uma ordem interna, o ordenamento jurídico, que é hierarquizado e autossuficiente. 
Sua obra mais conhecida, Teoria Pura do Direito, traduz, já em seu título, a preocupação de reduzir a complexidade da observação do fenômeno jurídico à normatividade, distinguindo a norma como o único objeto do sistema jurídico. É também seu objetivo investigar a validade do sistema, afirmando que o conteúdo e validade de toda e qualquer norma jurídica é a norma imediatamente superior, e isso, sucessivamente, até o último fundamento de validade do direito, que não é uma norma posta, mas pressuposta, a norma fundamental (KELSEN, 1998). E, nessa esteira, embora seja a teoria kelseniana expressão da racionalidade tradicional, cumpre ressaltar que ela acabou lançando as bases para uma teoria da supremacia da constituição, da expansão da jurisdição constitucional e do desenvolvimento de uma doutrina da interpretação constitucional, que, posteriormente, incorporará alguns elementos do pensamento sistêmico.

Veja-se, por conseguinte, que o positivismo jurídico, que encontra em Kelsen sua elaboração máxima, constitui-se a mais fidedigna expressão do padrão de racionalidade moderno, traduzindo perfeitamente os postulados de ciência do pensamento sistemático.

A simplicidade é representada pela busca da purificação do objeto do direito, que é a norma, excluindo-se os outros aspectos da realidade do campo jurídico. A objetividade traduz-se no mito de que a lei válida, emanada da autoridade competente, é a expressão máxima de racionalidade; e no mito de que a interpretação válida é a que observa o processo silogístico de subsunção dos fatos à norma. E a estabilidade está representada no dogma da completude e da autossuficiência do sistema jurídico.

Todavia, é preciso esclarecer que o século $\mathrm{XX}$ não foi marcado tão-somente pelo pensamento sistemático na ciência do direito, embora tenha sido o dominante. Paralelamente, principalmente a partir da segunda metade do século XX, começam a surgir novas formas de observar os fenômenos sociais e, como espécie desses, o fenômeno jurídico, como será demonstrado no tópico seguinte.

\section{Os reflexos do novo paradigma na ciência jurídica}

Na passagem do século XIX para o XX, principalmente mediante os estudos de Shopenhauer, Nietzche e Freud, inicia-se uma crítica ao racionalismo, defendendo-se a primazia da vontade sobre a razão (LOSANO, 2010, p. 117), o que tem reflexos no direito, com o surgimento, no início do século XX, do Movimento do Direito Livre e da Jurisprudência dos Interesses, ambos fundamentados no estudo do direito pelo seu viés finalístico e contrários 
ao reducionismo do Direito às normas jurídicas e à interpretação baseada em deduções lógicas, como defendido pelo positivismo de Kelsen. Tais movimentosserviram posteriormente de justificação às doutrinas totalitárias do direito, sobretudo na Alemanha nazista.

Após a Segunda Guerra Mundial, tem lugar um movimento filosófico de reflexão sobre a justiça e a função social do direito, de reavaliação do positivismo e de reaproximação entre o direito e a moral. Três teorias surgem como propostas de aplicação do Direito: a Teoria da Jurisprudência dos Valores (uma releitura da jurisprudência dos interesses), a Teoria do Sistema Móvel de Wilburg; e a Teoria do Sistema Aberto de Canaris.

Referindo-se à Jurisprudência dos Valores, LOSANO explica que essa teoria "procurou de várias formas conciliar a certeza do direito - sentida como um valor irrenunciável depois dos arbítrios do totalitarismo - com a flexibilidade necessária para decidir segundo a equidade dos casos-limite." (LOSANO, 2010, p. XXXIV). Importante destacar também que é, no contexto dessa teoria, que, na Alemanha, buscando dar uma fundamentação racional e um rigor metodológico a essa interpretação aberta a valores, Robert Alexy (1945) desenvolve sua teoria de argumentação "voltada à tarefa prática da ciência jurídica" (ALEXY, 2012, p. 38), deixando como legado uma teoria dos direitos fundamentais e sua famosa técnica de ponderação.

Sobre a Teoria do Sistema Móvel, de Walter Wilburg (1905/1991), LOSANO esclarece que o autor não propunha um sistema livre, mas sim um sistema que admitia certa flexibilidade diante das exigências do caso concreto mediante a aplicação dos princípios taxativamente previstos no ordenamento jurídico, sendo que o juiz seria livre para escolher o princípio mais adequado ou ainda para combinar mais de um princípio, na busca da equidade diante das particularidades impostas pelos fatos que lhe foram apresentados (LOSANO, 2010, P. 286).

Claus-Wilhelm Canaris (1937), na sua obra Pensamento Sistemático e Conceito de Sistema na Ciência do Direito, concebe o direito como um sistema teleológico e aberto, argumentando que o sistema interno do Direito (sistema objetivo) não precisaria ser completo e nele deveria incidir todos os valores, inclusive os de fora do sistema objetivo, presentes no meio externo ao direito (sistema científico). Na concepção do autor, o sistema jurídico é caracterizado pela ordenação e unidade. A ordem identifica o sistema jurídico a um conjunto de valores racionalmente apreensíveis que conduz o intérprete a uma aplicação do Direito com “adequação valorativa”; a unidade procura garantir a ausência de contradições da ordem jurídica, na medida em que promove a "realização da tendência generalizadora da justiça" 
(CANARIS, 1996, p. 21). Além disso, defende que, na práxis de aplicação do direito, a fim de que se comunique plena e acertadamente o conteúdo valorativo almejado pela norma e pelo sistema, é preciso conceber o sistema jurídico com as qualidades de abertura, heterogeneidade e mobilidade, abrindo-se uma exceção para que, nas raras hipóteses de conflito entre a “justiça material” e a "justeza sistemática", utilize-se de critérios extra-jurídicos positivos para alcançar a "justiça material” (CANARIS, 1996, p. 190-196). Portanto, pode-se afirmar que a teoria do sistema aberto de Canaris apregoa a prevalência do conteúdo sobre a formalidade e que seu "pensamento sistemático", na verdade, começa-se a voltar para um "pensamento sistêmico", como se esclarecerá adiante.

Outrossim, como consequência desse movimento de reflexão sobre a justiça e de uma reaproximação do Direito à Ética proposta pelas três teorias acima apresentadas, começase a cogitar em uma nova técnica argumentativa para a aplicação do direito.

É que se passa a perceber que a lógica dedutiva, cujo instrumento é o silogismo, servia perfeitamente ao rígido sistema do positivismo jurídico, mas essa nova forma de aplicar o Direito, mais sensível aos influxos dos valores, exigia outra estratégia discursiva, qual seja, a retórica, cujo pensamento é indutivo e o instrumento é a tópica e que, ao possibilitar a problematização a partir do caso concreto, também seria mais adequada a uma maior aproximação da solução jurídica ao ideal de justiça e de equidade.

Destacaram-se como pioneiros desses estudos, o polonês Chaïm Perelman (1912/1984), cuja obra mais famosa é Tratado da Argumentação: a nova retórica, e o alemão Theodor Viehweg (1907/1988), com sua obra Tópica e jurisprudência.

Chaïm Perelman é considerado o precursor da Teoria da Argumentação; ele recupera a retórica aristotélica que havia sido esquecida durante a Idade Média. Com sua teoria sobre o orador e os auditórios, o autor alerta para a importância do contexto e da verossimilhança, ou seja, para o fato de que a arte da persuasão tem como pressuposto a existência de vários e distintos pontos de vista (topoi), em contraposição à lógica, para qual há uma só verdade como ponto de partida; que o orador deve ser capaz de assimilar os diversos pontos de vistas argumentativos presentes nos espaços e práticas sociais, incorporando, inclusive, a linguagem daquele contexto, a fim de utilizá-los no discurso, de forma a conseguir credibilidade do auditório para argumentar e ir ganhando a adesão voluntária da comunidade dos espíritos/auditório (PERELMAN; OLBRECHTS-TYTECA, 2005).

Theodor Viehweg desenvolveu a Teoria da Argumentação, com ênfase na tópica, que é uma técnica de pensar por meio de problemas ou controvérsias práticas, promovendo uma 
discussão dialética, ou seja, que considere os diferentes pontos de vista, buscando um consenso em torno da solução mais adequada ao caso concreto num determinado contexto, oumelhor, individualizando o valor da justiça às peculiaridades do caso concreto (VIEHWEG, 2008)..

Veja-se, portanto, que essa proposta de raciocínio jurídico por meio da retórica ou da tópica compatibiliza-se à visão do direito como "sistema aberto", tanto que Canaris dedicou o último capítulo de sua obra Pensamento Sistemático e Conceito de Sistema na Ciência do Direito à tópica e, embora teça algumas críticas às elaborações de Viehweg, Canaris reconhece a importância dessa técnica discursiva nos casos em que a teoria sistemática clássica, com seu pensamento lógico dedutivo, não é capaz ser um instrumento adequado à solução dos problemas jurídicos (CANARIS, 1996, p. 245/289).

E as modificações na forma de pensar o "sistema e estrutura no direito" do século XX não se esgotam nas teorias já apresentadas. LOSANO, no terceiro volume da sua obra Sistema e estrutura no direito: do Século XX à Pós-Modernidade, ressalta que é característica marcante de correntes jurídicas da segunda metade do século XX a transposição direta ao direito de teorias científicas, tais como a cibernética, a teoria dos sistemas vivos, o estruturalismo, a linguística, a antropologia e, principalmente, a teoria sociológica de Luhmann (LOSANO, 2011, p. XXXII).

Entretanto, explica que há uma grande dificuldade dessas transposições de teorias científicas modernas e pós-modernas para o direito, representada pela utilização de uma difícil linguagem técnica que não é a do jurista; além disso, ressalta que, por parte dos juristas, há "dúvidas sobre a fecundidade cognoscitiva da transposição de teorias científicas no âmbito das ciências sociais", ressaltando que "muitas vezes, a transferência das ciências físico- naturais para as ciências sociais revelou-se não a aquisição de um método científico, mas a simples adoção de termos ou de metáforas", sem qualquer utilidade para o jurista (LOSANO, 2011, p. XXXIII).

Apenas para ilustrar algumas dessas transposições, tem-se, segundo LOSANO, o reflexo da cibernética na proposta da jurimetria (aplicação de métodos quantitativos para racionalizar o direito, como por exemplo, elaboração de modelos para auxiliar a tomada de decisão e o processamento eletrônico e estatístico de dados jurídicos; ) e da juscibernética, que redundou na informática jurídica e no direito da informática (ou direito eletrônico).

A respeito do estruturalismo, corrente científica que propõe o estudo da realidade formal como um conjunto formal de relações, LOSANO destaca que sua influência não foi 
tão intensa no direito, visto que superada pela teoria geral dos sistemas. Entretanto, é interessante citar, por exemplo, os reflexos do estruturalismo na obra do jurista brasileiro Tércio Sampaio Ferraz Junior, que, em seu livro "Teoria da Norma Jurídica”, reconhecendo a pluridimensionalidade do direito e a necessidade de escolher um ângulo de abordagem sem reduzi-lo ao mesmo, propõe-se a investigar o direito no viés normativo, sob o recorte lingüísticopragmático (FERRAZ JR, 2006).

Sem embargo de todas essas "transposições científicas", uma das que mais teve repercussão na ciência jurídica foi a "superteoria" de Luhmann: a autopoiese social. Nesse sentido, LOSANO esclarece que "até Luhmann estudou-se o sistema no direito; com Luhmann estuda-se o direito no sistema" (LOSANO, 2011, p. 425), isto é, Luhmann não se preocupou em explicar de que maneira as normas se organizam no ordenamento, como Kelsen o fez, mas voltou sua atenção para as relações entre o direito e outros subsistemas sociais, utilizando-se do pensamento sistêmico, cujos pressupostos são a complexidade, instabilidade e intersubjetividade, no lugar do tradicional paradigma sistemático.

Transpondo as observações de Maturana e Varela acerca da organização dos sistemas vivos para os sistemas sociais, Luhmann explica que há o fechamento estrutural do sistema, o que quer dizer que o ambiente não tem o poder de determinar, de fora, o comportamento do sistema, visto que o sistema se auto-organiza, relacionando-se com o ambiente de acordo com a coerência estrutural do momento e não conforme as instruções do ambiente. Mas, nessas interações, o que constitui a abertura cognitiva, o sistema acaba por modificar sua estrutura, visando sua própria conservação, ou seja, dentro da linha de adaptação, e, por isso mesmo, dentro dos limites da conservação de sua organização.

$\mathrm{Na}$ teoria de Luhmann, portanto, embora o subsistema do direito esteja sempre em comunicação com os outros subsistemas do ambiente social e dessa interação possa advir provocações (irritações) para a alteração na estrutura do direito, tais alterações só ocorrerão dentro de certas possibilidades estruturais, quais sejam, os mecanismos próprios de alteração do sistema jurídico, a fim de que o sistema não perca a sua organização e identidade, que é necessariamente invariante.

Por conseguinte, a teoria da autopoiese social, ao conceber o direito como um subsistema social, operativamente fechado e cognitivamente aberto, em acoplamento estrutural com os outros subsistemas sociais, permite uma observação mais ampla do direito, que não exclui a interação com valores morais, políticos, econômicos, culturais, etc e garante ao sistema uma maior adaptabilidade na busca do valor da justiça, o que é imprescindível 
numa sociedade hipercomplexa como a contemporânea. Mas a teoria da autopoiese social não patrocina que essa interação do direito ocorra de forma tão flexível quanto é defendido nas concepções de sistema aberto (teorias críticas ou alternativas) e que podem levar à fragilidadedas regras jurídicas e à instabilidade quanto à validade do direito para a regulação da sociedade.

Além disso, a teoria de Niklas Luhmann amplia o viés da intersubjetividade como pressuposto de ciência do novo paradigma, pois tem o proveito de pensar a sociedade, a partir de seus atores sociais mais importantes, que são as organizações. É uma mudança de paradigma: não se olha mais como o indivíduo decide o problema (correntes pós-positivistas que se concentram na teorização sobre a atividade de quem decide, ou seja, do julgador), mas como as organizações nos quais os indivíduos se inserem tomam suas decisões.

Exposto tal quadro de referências teóricas para o direito do século XXI, é preciso destacar ainda que a globalização econômica e as três crises que lhe são decorrentes (a de soberania, do estado e do direito) também impõem uma mudança paradigmática à ciência jurídica. À vista dessa realidade, os sistemas jurídicos nacionais, representados por suas Constituições, passam por um papel de "hipertrofiamento político-simbólico" (NEVES, 2011, p. 200) e por uma "liquefação" do seu poder de controle político e social, o que obriga ao direito, se quiser sobreviver aos tempos, a uma séria reflexão acerca da adequação de seus pressupostos, enquanto ciência e técnica de uma sociedade pós-moderna. São muitos os autores que refletem sobre os influxos da globalização e do pensamento sistêmico na ciência jurídica, destacando-se aqui o jurista alemão Günther Teubner (1944), que o faz numa perspectiva sociológica, o jurista brasileiro Marcelo Neves (1957), com sua teoria de transconstitucionalismo (NEVES, 2012), e o professor José Eduardo Faria (1949), com suas acessíveis e conhecidas publicações sobre o direito e a globalização (FARIA, 2004).

Diante de todo esse quadro de teorias do breve, mas intenso século XX, LOSANO chega à conclusão que "o pensamento sistemático tradicional conserva sua validade na aplicação do direito à maioria dos casos concretos, claramente subsumíveis nas normas estatuídas pelo legislador" (LOSANO, 2010, p. XXV), entretanto, nos “casos-limite”, ou seja, nos casos em que a resposta adequada não está taxativamente prevista no sistema ou, nos quais, não é possível encontrar a solução de equidade utilizando-se da metodologia lógico- dedutiva do pensamento sistemático, deve-se, na visão do autor, recorrer "a uma referência a princípios não formulados pelo legislador (ou seja, a valores) que ajuda a resolver os casos- limite" (LOSANO, 2010, p. XXV). Acresça-se ainda que é, nesses “casos-limite”, que se costuma utilizar a técnica 
da ponderação de valores, com relação à qual Alexy tentou construir uma teoria de justificação racional.

No mesmo sentido, é a tese sustentada por LORENZETTI, na sua obra Teoria da Decisão Judicial. O autor fala na coexistência do "sistema de validade formal", que se utiliza do "raciocínio sistemático e do juízo apriorístico (ou juízo analítico - são universais e necessários e prescindem da experiência)" e do "sistema de validade material", que se utiliza do pensamento casuístico, podendo partir de conhecimentos fragmentários e "conta com o juízo problemático, a tópica e a argumentação jurídica", defendendo que "ambas as perspectivas são complementares, razão pela qual deve ser adotado um juízo prático, mas com vinculações sistemáticas" (LORENZETTI, p. 2010, p. 76).

Por conseguinte, percebe-se que, na visão contemporânea de muitos juristas, como LOSANO e LORENZETTI, a proposta, com relação à ciência jurídica, não é a superação do paradigma de pensamento sistemático pelo pensamento sistêmico, mas a combinação dos dois modelos de cientificidade, sobretudo, no pertinente à prática jurídica.

\section{Considerações Finais}

Restou demonstrado que a ciência jurídica sofreu os influxos das mudanças paradigmáticas das ciências em geral, estando, na atualidade, num processo de reconstrução de suas bases, tão arraigadas ao pensamento sistemático, para uma adaptação paulatina aos pressupostos da complexidade, instabilidade e intersubjetividade do pensamento sistêmico. Tal reformulação não é apenas uma exigência epistemológica, mas também pragmática, visto que novos pressupostos para a ciência resultam não só da evolução do conhecimento, sendo igualmente fruto de novas relações e demandas da sociedade.

Como visto, em suas origens, os conceitos e as estruturas do direito foram guiados pelo pensamento problemático, que era fragmentário, prático-casuístico e esparso, além de, muitas vezes, mesclado a outras formas de conhecimento, como o moral ou o religioso.

Posteriormente, esse acúmulo de conhecimento foi sendo organizado e sistematizado, atingindo o ápice de sua elaboração no positivismo jurídico de Kelsen, autêntica tradução do paradigma sistemático, sendo a simplicidade manifestada na redução epistemológica do direito à norma e ao ordenamento; a objetividade representada pelo mito da validade da lei, do ordenamento e do processo silogístico como forma de interpretação; e a estabilidade simbolizada no dogma da completude e da autossuficiência do sistema jurídico. 
Mas o direito novecentista não se limitou ao positivismo jurídico. Consoante o exposto, no início do século XX, teve lugar o Movimento do Direito Livre e a Jurisprudência dos Interesses e, no período pós-guerra, inicia-se a reflexão acerca da função social do direito, que redunda numa reavaliação do positivismo e da concepção fechada de sistema jurídico, propondo-se uma abertura do sistema, a reaproximação entre o direito e a ética e a recuperação da retórica e da tópica como modos de interpretação jurídica. Ademais, há a tentativa de transposição ao direito das teorias cibernéticas e dos sistemas, com a valorização das observações sociológicas do direito, que procuram pensar não o sistema do direito e sim o direito no sistema social.

Por conseguinte, é possível inferir, do quadro de teorias jurídicas apresentadas no último tópico desse artigo, uma atenuação gradual dos pressupostos do paradigma sistemático, tão bem representados pelo positivismo jurídico e pela lógica dedutiva, e uma aproximação do direito aos pressupostos do pensamento sistêmico.

As correntes teóricas que pregam a abertura do sistema jurídico e a reaproximação do direito à ética, por exemplo, constituem indicativos de enfraquecimento dos pressupostos da simplicidade e da estabilidade.

De um lado, admite-se que os fenômenos jurídicos são complexos, sujeitos à interferência de outros sistemas, como o ético, político, econômico, cultural, não podendo ser reduzidos ao aspecto da norma e do ordenamento jurídico. E isso porque a sociedade contemporânea que o direito pretende regular também é hipercomplexa, caracterizada por um forte pluralismo cultural, uma intensa comunicação e a existência de múltiplos centros normativos. A primeira característica mitiga a crença da existência de uma só verdade (a norma), no qual se assenta o raciocínio lógico-dedutivo, forçando o direito a considerar que vários podem ser os pontos de vista (econômico, político, cultural, ético, etc); o segundo aspecto desestabiliza a primazia das fontes estatais e dos ordenamentos jurídicos nacionais na regulação das relações sociais. Nesse cenário, não há como insistir no velho pressuposto da simplicidade. É preciso, portanto, começar a considerar o esgotamento do modelo de pureza epistemológica buscada por Kelsen (simplicidade), acolhendo a tendência à transdiciplinariedade (e transconstitucionalidade) proposta pelo pressuposto da complexidade do pensamento sistêmico.

Noutra alheta, constata-se que não é mais possível prever e controlar todas as situações jurídicas por meio de regras taxativas (dogma da completude); que o ordenamento jurídico não é capaz de acompanhar todas as rápidas mudanças sociais; que, aliás, o mundo vive uma crise da soberania, do estado e do direito, no qual os sistemas jurídicos nacionais vão perdendo exclusividade na regulamentação das relações sociais, existindo uma multiplicidade de centros 
de poder e de regulação; que, se o sistema jurídico quiser sobreviver ao ritmo da sociedade e à globalização, terá de ser composto por normas com uma maior abertura interpretativa, que possibilite uma maior comunicação com outros subsistemas sociais e uma maior adaptabilidade ao meio, bem como desenvolver técnicas de elaboração, interpretação e aplicação mais afetas ao pressuposto da instabilidade e à realidade de um ordenamento jurídico estatal cada vez mais "líquido" e frágil.

Por sua vez, o surgimento, ou melhor, a recuperação de novas formas de argumentação jurídica, pautadas pela retórica e pela tópica, traduz a atenuação do pressuposto da objetividade e a assunção do pressuposto da intersubjetividade. Reconhece-se que não há uma realidade independente do observador, ou seja, independente do contexto no qual estão inseridas as organizações que produzem as normas e desvinculada dos valores dos intérpretes da norma e que, portanto, todo conhecimento e toda ciência é tão somente um espaço de consenso. O reflexo disso na prática jurídica, além do arrefecimento da lógica-dedutiva como única forma interpretação, é a busca de um direito cada vez mais consensual em todos os processos de elaboração e aplicação, o que é possibilitado pelo uso da retórica e da tópica como técnicas de argumentação.

Cumpre lembrar ainda que, conforme exposto no último tópico desse artigo, a sugestão pragmática contemporânea de alguns juristas não é a substituição do paradigma sistemático pelo sistêmico, mas a conciliação dos dois modelos de cientificidade no modo de fazer o direito, aplicando-se o pensamento sistemático à generalidade das situações e o pensamento problemático, num viés sistêmico, representado pela tópica jurídica e a nova teoria da argumentação, aos "casos-limites", como uma opção de harmonização entre a segurança jurídica (estabilidade) e a busca de justiça material, que exige do sistema jurídico uma maior abertura e flexibilidade diante do pluralismo cultural e das novas demandas sociais.

Enfim, espera-se que o desfecho seja apenas o início, ou seja, que a "síntese da síntese" ora apresentada de tantas teorias científicas e jurídicas sirvam à reflexão, pelo leitor, de como a interação entre todos esses modelos teóricos do passado e as propostas do presente têm influenciado o 'modo de dizer' e o 'modo de fazer' o direito no cotidiano da academia e da prática jurídica. 


\section{REFERÊNCIAS}

ALEXY, Robert. Teoria dos Direitos Fudamentais. 2. ed. Tradução Virgílio Afonso da Silva. São Paulo: Malheiros Editores, 2012.

BERTALANFFY, Ludwig Von. Teoria geral dos sistemas: fundamentos, desenvolvimento e aplicações. 4. ed Petrópolis: Vozes, 2009.

BARROSO, Luís Roberto. Curso de Direito Constitucional Contemporâneo: os conceitos fundamentais e a construção do novo modelo. 3. ed. São Paulo-SP: Saraiva, 2012.

CANARIS, Claus-Wilhelm. Pensamento sistemático e conceito de sistema na ciência do direito. 2. ${ }^{a}$ ed. Lisboa: Fundação Calouste Gulbenkian, 1996.

CAPRA, Fritjof. A Teia da vida: uma nova compreensão científica dos sistemas vivos. São Paulo: Cultrix, 1996.

DINIZ, Maria Helena. Compêndio de introdução à ciência do direito. 18. ed. São Paulo: Saraiva, 2007.

FARIA, José Eduardo. O direito na economia globalizada. São Paulo: Saraiva, 2004.

FERRAZ JR, Tércio Sampaio. Teoria da norma jurídica: ensaio de pragmática da comunicação normativa. 4. ed. Rio de Janeiro: Editora Forense, 2006.

HESPANHA, António Manuel. Cultura Jurídica Europeia. Florianópolis: Boiteux, 2005.

KELSEN, Hans. Teoria pura do direito. 6. ed. São Paulo: Martins Fontes, 1998.

LORENZETTI, Ricardo Luis, Teoria da decisão judicial: fundamentos do Direito. 2. ed. São Paulo: RT, 2010, p. 76

LOSANO, Mario G. Sistema e estrutura no direito, volume 1: das origens à escola histórica. Tradução Carlos Roberto Dastoli. São Paulo: Martins Fontes, 2008.

Sistema e estrutura no direito, volume 2: o século XX. Tradução Luca Lamberti;

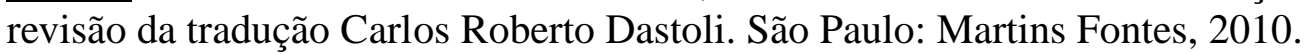

Sistema e estrutura no direito, volume 3: do século XX à pós-modernidade. Tradução Carlos Roberto Dastoli. São Paulo: Martins Fontes, 2011.

LUHMANN, Niklas. Introdução à Teoria dos Sistemas. 3.ed. Petrópolis-RJ: Vozes, 2011.

MATURANA, Humberto. VARELA, Francisco. A árvore do conhecimento: as bases biológicas do entendimento humano. Campinas-SP: Ed. Psy, 1995.

NEVES, Marcelo. A constitucionalização simbólica. 3 ed. São Paulo: Martins Fontes, 2011. NEVES, Marcelo. Transconstitucionalismo. São Paulo: Martins Fontes, 2012 
PERELMAN, Chäim; e OLBRECHTS-TYTECA, Lucie. Tratado da argumentação: a nova retórica. 2. ed. Trad. Maria Ermantina Galvão G. Pereira São Paulo: Martins Fontes, 2005.

SÓFOCLES. A Trilogia Tebana. 9. ed. Trad. Mário da Gama Kury. Rio de Janeiro: Zahar Editores, 2001.

VASCONCELlOS, Maria José Esteves. Pensamento sistêmico: o novo paradigma da ciência. Campinas-SP: Papirus, 2002.

VIEHWEG, Theodor. Tópica e jurisprudência: uma contribuição à investigação dos fundamentos jurídico-científicos. 5. ed. Trad. Kelly Susane Alflen da Silva. Porto Alegre: Sergio Antonio Fabris Editor, 2008

WIENER, Norbert. Cibernética e sociedade: o uso humano de seres humanos. $4^{\mathrm{a}}$ ed. São Paulo: Cultrix, 1973. 